\title{
1 Factors associated with eating out of home in Vietnamese adolescents
}

2 Lachat $\mathrm{Carl}^{1,2}$, Khanh Le Nguyen Bao ${ }^{3}$, Huynh Thi Thanh Tuyen ${ }^{2}$, Verstraeten

3 Roosmarijn ${ }^{2}$, Nago Eunice ${ }^{2,4}$, Roberfroid Dominique ${ }^{1}$, Kolsteren Patrick ${ }^{1,2, *}$

4

$5{ }^{1}$ Nutrition and Child Health Unit, Institute of Tropical Medicine, Nationalestraat 155 B-

62000 Antwerp, Belgium;

$7 \quad{ }^{2}$ Department of Food Safety and Food Quality, Faculty of Bioscience Engineering,

8 Ghent University, Coupure links 653, 9000 Gent, Belgium;

$9{ }^{3}$ National Institute of Nutrition, Tang Bat Ho 48b, Hanoi, Vietnam;

$10{ }^{4}$ Department of Nutrition and Food Science, Faculty of Agricultural Sciences,

11 University of Abomey-Calavi, 01 BP 526 Cotonou, Benin;

13 Email adresses:

14 clachat@itg.be (C. Lachat), bkhanhnin@gmail.com (B. Khanh);

15 thanhtuyen2054@yahoo.com; (T. Huynh) roosmarijn.verstraeten@UGent.be (R.

16 Verstraeten), eun_nago@yahoo.fr (E. Nago); DRoberfroid@itg.be (D. Roberfroid);

17 pkolsteren@itg.be (P. Kolsteren)

19 Keywords: Eating; Life Style; Food Habits; Vietnam; Adolescents

20 Running head: Associations of eating out in Vietnam

21 Number of words: 3100

22 Number of tables: 4

23 Number of figures: 1

24 Additional files: 1 
1 List of abbreviations used

2 BMI Body Mass Index

3 IQR Inter Quartile Range

$4 \mathrm{OH} \quad$ Out of Home

5 OR Odds Ratio

6 RE Retinol Equivalents

7

8 * Corresponding author

9 Patrick Kolsteren

10 Nutrition and Child Health Unit, Institute of Tropical Medicine,

11 Nationalestraat 155 B-2000 Antwerp, Belgium

12 "not for publication"

13 Tel: 003232476389 fax: 003232476543 pkolsteren@itg.be

14

15

16

17

18 


\section{Abstract}

2 Eating out of home $(\mathrm{OH})$ is nutritionally important in some developing countries. This

3 study identifies the factors associated with eating $\mathrm{OH}$ in Vietnamese adolescents. Data

4 was obtained from a cross-sectional cluster survey of 502 adolescents in rural and urban

5 areas in Vietnam. Factors associated with eating $\mathrm{OH}$ were recorded with a Likert scale

6 and analysed using factor analysis. Data on eating $\mathrm{OH}$ was collected using a frequency

7 questionnaire and a 1-day $24 \mathrm{~h}$ recall. A first pattern "Convenience" incorporated

8 preparation time, price, variety, taste, proximity and social aspects as items associated

9 with eating $\mathrm{OH}$. A second pattern "Nutritional and food safety concerned" reflects

10 concerns with regard to hygiene, fat and salt content of the food prepared $\mathrm{OH}$.

11 Adolescents characterised by the convenience pattern were more likely $(\mathrm{OR}=1.51$,

$12 \mathrm{P}<0.001)$ to eat $\mathrm{OH}$ more frequently. The highest tertile of the Nutritional and food

13 safety concerned pattern was less likely $(\mathrm{OR}=0.61, \mathrm{P}=0.03)$ to eat $\mathrm{OH}$ compared to

14 lower tertiles. Both patterns were not associated with the \% energy from eating $\mathrm{OH}$ per

15 day. Convenience and to a lesser extent nutritional and food safety concerns are

16 significant factors associated with the frequency of eating $\mathrm{OH}$ in Vietnamese

17 adolescents. 


\section{Introduction}

Foods prepared out of home $(\mathrm{OH})$ have taken a predominant place in the diet worldwide

(Bezerra \& Sichieri, 2009; Orfanos et al., 2009; Vandevijvere et al., 2009). This is potentially worrying since data from the USA indicate that increased eating $\mathrm{OH}$ is an important driver of the obesity epidemic (Kant \& Graubard, 2004). Those who eat more OH tend to have a higher energy intake (French et al., 2001; Satia et al., 2004; Taveras et al., 2005) and a higher body mass index (BMI) (Kant \& Graubard, 2004; Thompson et al., 2004; Bezerra \& Sichieri, 2009). Although data on the nutritional importance of eating $\mathrm{OH}$ is scanty for low- and middle-income countries, researchers also argued that increases in eating $\mathrm{OH}$ have been fuelling the dietary changes in these countries (Adair \& Popkin, 2005).

Vietnam is a country affected with various nutritional deficiencies (Thang \& Popkin, 2003). At the same time, diet-related diseases such as obesity are emerging rapidly in urban areas of the country (Hong et al., 2007; van Lierop et al., 2008). Since adolescents represent a large share of the population in low- and middle-income countries and since eating habits are known to track from adolescents into adulthood (Kelder et al., 1994), they are a key target group for public health interventions (WHO, 2003).

In contrast to the literature in high income countries, eating $\mathrm{OH}$ in Vietnam has a number of beneficial nutritional characteristics. In a sample of school going adolescents, $\mathrm{OH}$ foods accounted for $21 \%$ of the total daily energy intake and provided substantial amounts of fruits, vegetables, $\mathrm{Fe}$ and $\mathrm{Zn}$. At the same time however, eating $\mathrm{OH}$ was positively associated with a higher energy intake from fat and the consumption of sugary products (Lachat et al., 2009). 
Improving eating $\mathrm{OH}$ is a potential interesting way to improve dietary intakes of large populations (You et al., 2009). When developing interventions to improve dietary habits and eating OH however, contexts-specific determinants (Sandvik, et al., 2010; Ruxton \& Kirk, 1996) of eating behaviour need to be taken into account. Data mainly from high income countries have shown that the dietary quality tends to increase with socio-economic status (Darmon \& Drewnowski, 2008) and that factors such as demography (Jackson et al., 2003; Kremers et al. 2007; Wang et al. 2002), gender (Kremers et al., 2007; Lien et al., 2002; Milligan et al., 1998; Neumark-Sztainer et al., 2003) household wealth status (Ruxton \&

50 Kirk, 1996; Neumark-Sztainer et al., 2003; Bere et al.,2008) and parental education level (Ruxton \& Kirk, 1996; Neumark-Sztainer et al., 2003; van der Horst et al., 2007) are significant factors associated with the quality of adolescents' diets.

Despite its nutritional importance, quantitative and qualitative data on the associations of eating $\mathrm{OH}$ is lacking for low- and middle-income countries. The aim of this study was to identify the factors associated with eating $\mathrm{OH}$ in Vietnamese adolescents and to evaluate their association with dietary intake, the frequency of eating $\mathrm{OH}$ and the energy contribution of eating $\mathrm{OH}$ on a daily basis.

\section{Materials and methods}

\section{Sample}

Data was obtained from a cross-sectional cluster survey of adolescents from 4 schools in Hanam and 4 schools in Hanoi in Vietnam in 2006-2007. All children of grade 11 in each school were invited to participate. In a first survey, food intake and anthropometric data were collected and in a second survey the same adolescents completed a form with socio-economic 
information and factors associated with eating $\mathrm{OH}$. The selection of the schools was done by the Vietnamese authorities to make sure that the schools did not have an intervention that would bias our findings.

The study protocol was approved by the Medical Research Ethics Committee of the National Institute of Nutrition of Vietnam. Written informed consent was obtained from the adolescents and their parents prior to data collection.

Anthropometric measurements (weight and height) were carried out in double by experienced researchers. Age (calculated from date of birth from the medical records at school) and gender specific cut-off values were used to determine BMI categories (Cole et al., 2000; Cole et al., 2007). Since only 2 adolescents in the sample were obese, the categories of 'obese' and 'overweight' were merged into one category 'overweight' for the analysis.

\section{Eating $\mathrm{OH}$}

Eating $\mathrm{OH}$ was assessed using both the frequency of eating $\mathrm{OH}$ and the $\%$ energy intake from $\mathrm{OH}$ foods on a daily basis. Data on the frequency of eating $\mathrm{OH}$ were collected using 6 frequency questions (taking breakfast from the school tuck shop, taking lunch at the school, eating $\mathrm{OH}$ during schooldays, eating $\mathrm{OH}$ during weekend days, drinking soft drinks $\mathrm{OH}$ during schooldays and drinking soft drinks $\mathrm{OH}$ during weekend days). The answers were summed to produce a total score for weekly frequency of eating $\mathrm{OH}$. The $\%$ energy intake from $\mathrm{OH}$ foods was measured with a 1 day interviewer administered 24-hour recall. All foods and drinks prepared $\mathrm{OH}$ were classified as $\mathrm{OH}$ foods, regardless of their place of

90 consumption. The composition of the foods and drinks was obtained from the Vietnamese food composition table (National Institute of Nutrition, 1972). We used a dietary diversity 
score as a measure of dietary quality as described earlier (Kennedy et al., 2007) by counting food groups: cereals, root/tubers, vegetables, fruits, meat/poultry/offal, eggs/dairy, fish/seafood, pulses/legumes/nuts, oil/fats, sugar/confectionary/soft drinks and miscellaneous

95 (inc. spices and alcohol) for which at least $10 \mathrm{~g}$ was consumed per day. The classification was based on food groups used at the National Institute for Nutrition in Vietnam. To calculate energy density, the energy contribution from all food and drinks consumed was divided by the weight. Since both the frequency of eating $\mathrm{OH}$ and the \% energy from $\mathrm{OH}$ food were highly skewed, both variables were categorised as tertiles for the analysis.

100

\section{Socio-economic data}

We used location (Hanam as rural and Hanoi as urban) of schools, household wealth, amount of pocket money, gender and education of the parents as socio-economic variables. We recorded household assets such as air-conditioning, refrigerator, car, television, motorcycles, computer and the type of house and converted them into their financial equivalent as a measure of household wealth status. The weekly amount of pocket money of the adolescents was used as a proxy of individual wealth. We compared the highest tertile (indicated as "high") with the two lowest tertiles (indicated as "lower") of the wealth variables. The education level of the parents was grouped as "College, university or higher education" and "Senior secondary or lower".

\section{Factors associated with eating $\mathrm{OH}$}

Focus group discussions with the adolescents in 2 rural and 2 urban schools were carried out to obtain the most important factors associated with eating $\mathrm{OH}$. Each focus group comprised

115 8-10 participants and was balanced in terms of gender. The discussions were exploratory using open ended questions, moderated by an experienced Vietnamese researcher, recorded 
digitally and transcribed manually. Recurring factors were retained as associations of eating $\mathrm{OH}$. The factors associated with eating $\mathrm{OH}$ were recorded in a 5-option Likert scale (Likert, 1932). We added the option "I don't know" since we were unsure how well the adolescents

120 could fill out the scales. A pretest in a neighbouring school (not included in the sample) showed that adolescents had no difficulty with the forms and that the different constructs of the test version had an acceptable internal consistency (Cronbach's $\alpha=0.70$ ). The final questionnaire contained items with a Cronbach's $\alpha=0.73$ (Additional file 1). The consistency of the questions in rural and urban areas separately were both acceptable (Cronbach's $\alpha=0.70$

125 and $\alpha=0.76$ respectively). "I don't know" responses were recoded as missing. Only adolescents that provided valid responses (all answers apart from missing and "I don't know") for $>80 \%$ of the questions were retained for analysis.

\section{Analysis}

130 Data were entered in double using EpiData (Odense, Denmark) and analysed using Stata (StataCorp, Texas, USA). Factor analysis was used to identify patterns in the associations of eating $\mathrm{OH}$. The covariance matrix was rotated to produce orthogonal and independent factors. A screeplot of eigenvalues and the Kaiser criterion (Kaiser, 1960) were used to select the factors for analysis. Factors retained for analysis were subsequently examined visually for

135 meaningful patterns in associations of eating $\mathrm{OH}$. Items with factor loadings $>0.3$ were considered to be more important in explaining variability in the factors and were taken into account to identify patterns in the associated factors. The factors retained for analysis were categorised into tertiles in the models.

140 The association of the factors of eating $\mathrm{OH}$ was analysed using 2 dependent variables: frequency of eating $\mathrm{OH}$ per week and \% energy intake from $\mathrm{OH}$ foods on a daily basis. 
Differences in dietary intake between the patterns of factors were analysed using a KruskalWallis test. Since intakes of fruit and vegetables, vitamin A, Na, Fe and Zn potentially depend on the energy consumed, we used energy adjusted estimates in the models (Willett,

145 1998). The socio-economic associations with the associated factors and frequency of eating OH were analysed using logit models for ordinal dependent variables (Williams, 2006). Predictors with $\mathrm{P}<0.20$ in a bivariate model were included in an adjusted model. Ordinal regression models only provide valid estimates when the odds ratios (OR) of the sub-models are proportional. When the OR were not proportional (as assessed using a Likelihood-ratio

150 test), we reported the results of the sub-models in the text.

We previously observed differences of eating $\mathrm{OH}$ in rural and urban areas and tested for interactions of locality and factors associated with eating $\mathrm{OH}$. The interaction terms were considered significant at $\mathrm{P}_{\mathrm{i}}<0.10$. All other analyses were carried out with a significance level 155 of $\mathrm{P}<0.05$. Given the highly skewed distribution, the frequency of eating $\mathrm{OH}$ is reported as median and interquartile range (IQR). All other data are reported as means and SD, adjusted for the clustering in schools.

\section{Results}

160

\section{Characteristics of the respondents}

Complete data were available for 502 adolescents. In total 8 adolescents were excluded from analysis because they did not provide valid responses. A total of 308 adolescents (61\%) were from rural areas. On average the adolescents were $16.4 \pm 0.4$ years with a BMI of $19.5 \pm 2.3$

$165 \mathrm{~kg} \cdot \mathrm{m}^{-2}$ with no significance differences in rural and urban areas $(\mathrm{P}=0.25$ and $\mathrm{P}=0.60$ for age 
and BMI respectively). Of the total sample, $22.0 \%, 4.0 \%$ and $0.4 \%$ were underweight, overweight and obese respectively.

\section{Frequency and energy contribution of eating $\mathrm{OH}$}

170 One quarter $(27.3 \%)$ of the adolescents did not have any food or beverage $\mathrm{OH}$ on a weekly basis. The median of the frequency of eating $\mathrm{OH}$ was 3 times a week (IQR=0-7). Children in urban areas (Median=5 times, IQR=1-9) consumed $\mathrm{OH}$ foods more frequently on a weekly basis compared to those in rural areas (Median=1 / week, IQR=0-3). Females (Median=3/ week, $\mathrm{IQR}=1-8$ ) ate more frequently $\mathrm{OH}$ compared with males (Median=2 / week, IQR=0-7),

175 though this difference was marginally not significant $(\mathrm{P}=0.07)$. Compared with normal BMI adolescents, underweight and overweight adolescents did not significantly eat out more often $(\mathrm{P}=0.39$ and $\mathrm{P}=0.24$ respectively)

On average, adolescents in the sample consumed $24.6 \pm 20.3 \%$ of their daily energy intake

180 from $\mathrm{OH}$ foods. The energy contribution from $\mathrm{OH}$ foods was lower in rural areas compared to urban areas $(13.4 \pm 15.3 \%$ energy per day in rural vs. $31.6 \pm 20.0 \%$ energy per day in urban areas). On a daily basis, females had a higher energy contribution from eating $\mathrm{OH}$ compared with males $(27.5 \pm 21.5 \%$ and $19.5 \pm 16.8 \%$ of the total energy intake respectively, $\mathrm{P}<0.001)$. Underweight children did not have different \% daily energy contribution from $\mathrm{OH}$ eating compared to normal $\mathrm{BMI}$ children $(\mathrm{P}=0.78)$. Overweight children had a higher daily energy contribution from $\mathrm{OH}$ eating compared to normal BMI children $(35.3 \pm 26.5 \%$ vs. $24.3 \pm 20.0 \%)$ but this difference was marginally not significant $(\mathrm{P}=0.055)$. 
190 Two factors, explaining almost $60 \%$ of the variability in the matrix were retained for analysis (Figure 1). We identified 2 patterns: a first one labelled "Convenience" pattern that was characterised by short preparation time, taste, low price and variety of foods offered $\mathrm{OH}$ and proximity to school and opportunity to meet friends when eating $\mathrm{OH}$ (Table 1). The second one incorporated items related to the fat and salt content and food safety aspects of the food served $\mathrm{OH}$ and was labelled "Nutritional and food safety concerned" pattern. The factor analysis produced similar results when carried out for adolescents in rural and urban areas separately (not shown).

In contrast to the Nutritional and food safety concerned pattern, the Convenience pattern was associated with differences in dietary intake per day. Adolescents with higher scores for Convenience had a lower total energy and energy density on a daily basis (Table 2). The profiles were not associated with differences in other dietary parameters.

\section{Convenience and eating $\mathrm{OH}$}

205 Adolescents with higher scores for the Convenience pattern were more likely to report higher frequencies of eating $\mathrm{OH}$ (Table 3). Higher tertiles of Convenience were $50 \%$ more likely to report higher frequencies of eating $\mathrm{OH}$. The $\mathrm{OR}$ of the models with frequency of eating $\mathrm{OH}$ as outcome were not proportional $(\mathrm{P}<0.001)$. Adolescents in the highest tertile of "Convenience" ate more frequently $\mathrm{OH}$ compared to the 2 lower tertiles $(\mathrm{OR}=1.97, \mathrm{P}<0.001)$.

210 Similarly, the adolescents in the 2 highest tertiles of Convenience ate $\mathrm{OH}$ more frequently compared to the lowest tertile $(\mathrm{OR}=1.74, \mathrm{P}=0.005)$. The Convenience pattern was not associated with higher energy intakes from $\mathrm{OH}$ foods on a daily basis. The OR of the models was proportional $(\mathrm{P}=0.54)$. 
215 The interaction between the Convenience pattern and location was significant in the model with frequency of eating $\mathrm{OH}$ as an outcome $\left(\mathrm{P}_{\mathrm{i}}=0.003\right)$ and the model with \% energy from $\mathrm{OH}$ foods $\left(\mathrm{P}_{\mathrm{i}}=0.004\right)$. The association of the Convenience pattern with frequency of eating $\mathrm{OH}$ was particularly present in the urban area $(\mathrm{OR}=1.65, \mathrm{P}=0.02)$ and less in the rural one $(\mathrm{OR}=1.31, \mathrm{P}=0.05)$. The Convenience pattern was not associated with $\%$ energy of $\mathrm{OH}$ foods 220 in either rural $(\mathrm{OR}=0.89, \mathrm{P}=0.55)$ or urban $(\mathrm{OR}=1.17, \mathrm{P}=0.22)$ areas.

The interaction between the Convenience pattern and gender was not significant in the model with frequency of eating $\mathrm{OH}\left(\mathrm{P}_{\mathrm{i}}=0.48\right)$ but it was so in the model with $\%$ energy contribution from $\mathrm{OH}$ eating $\left(\mathrm{P}_{\mathrm{i}}=0.02\right)$. Stratified analysis of the latter model however, revealed no gender

225 differences in the association of convenience and \% energy contribution of $\mathrm{OH}$ eating (females: $\mathrm{OR}=1.05, \mathrm{P}=0.68$; males: $\mathrm{OR}=1.10, \mathrm{P}=0.44$ ).

\section{Nutritional and food safety concerns and eating $\mathrm{OH}$}

Overall, the Nutritional and food safety concerned pattern was not associated with the

230 frequency of eating $\mathrm{OH}$ (Table 4). The OR of both categories of the Nutritional and food safety concerned pattern however, were not proportional for the model comparing frequency of eating $\mathrm{OH}(\mathrm{P}<0.001)$. Adolescents in the highest tertile of Nutritional and food safety concerned pattern were $40 \%(\mathrm{OR}=0.61, \mathrm{P}=0.03)$ less likely to eat $\mathrm{OH}$ compared to those in the lowest 2 tertiles. The OR comparing the adolescents in the lowest tertile vs. the highest 2 235 tertiles were not significant $(\mathrm{OR}=0.88, \mathrm{P}=0.30)$.

The Nutritional and food safety concerned pattern was not associated with differences in \% energy contribution from $\mathrm{OH}$ foods. The $\mathrm{OR}$ for the model with $\%$ energy from $\mathrm{OH}$ foods as outcome were proportional $(\mathrm{P}=0.52)$. 
Although the interaction between locality and the Nutritional and food safety concerned pattern was significant $\left(\mathrm{P}_{\mathrm{i}}=0.004\right)$ in the model with frequency of eating $\mathrm{OH}$ as outcome, no differences were observed in rural and urban areas.

245 The interaction between gender and the Nutritional and food safety concerned pattern was significant for both models with frequency of eating $\mathrm{OH}$ as outcome $\left(\mathrm{P}_{\mathrm{i}}=0.08\right)$, and energy \% contribution from $\mathrm{OH}$ foods $\left(\mathrm{P}_{\mathrm{i}}=0.04\right)$. The stratified analysis however, showed no differences between the genders in either the association of Nutritional and food safety concerned patterns with the frequency of eating $\mathrm{OH}$ (females: $\mathrm{OR}=0.87, \mathrm{P}=0.39$; males:

$250 \mathrm{OR}=0.63, \mathrm{P}=0.16$ ) or the $\%$ energy contribution from $\mathrm{OH}$ foods (females: $\mathrm{OR}=0.93, \mathrm{P}=0.66$; males: $\mathrm{OR}=0.86, \mathrm{P}=0.45)$.

\section{Discussion}

Context-specific, culturally acceptable and population based strategies are required to address the prevailing nutritional problems effectively. Eating $\mathrm{OH}$ is important in the diet of Vietnamese adolescents in particular those residing in urban areas and offers a potential effective way to address the current dietary challenges.

A pattern of convenience towards eating $\mathrm{OH}$ was associated with higher frequencies of eating

$260 \mathrm{OH}$ per week and lower energy intake and energy density per day. The items characterising this pattern were fast preparation time, cheap price, taste and variety of the food, proximity, opportunity to meet friends and not having to cook at home. These findings support those of previous studies that have looked at determinants of eating habits. Taste of the food offered, convenience and the opportunity to meet friends are known to be important reasons for eating 
265 OH (Rydell et al., 2008; Lucan et al., 2010). Data from Nairobi have shown how households with less time available to prepare food at home ate out more frequently (van't Riet et al., 2001). Proximity of eating establishments has been reported earlier to be a key factors associated with eating $\mathrm{OH}$ for school going adolescents in the USA (Davis \& Carpenter, 2009). Studies have argued that the dietary environment has a profound influence on diets of 270 individuals (Story et al., 2002; Swinburn et al., 1999) but the association of proximity of eating establishment (in particular fast food outlets) and dietary quality or nutritional status however, is inconsistent (Cummins \& Macintyre, 2006). The adolescents in our study reported eating $\mathrm{OH}$ was "a part of modern life" as an item associated with eating $\mathrm{OH}$. Warde and Martens previously described how eating $\mathrm{OH}$ in the UK is associated with sophistication 275 and style (Warde \& Martens, 1998).

A second pattern of factors associated with eating $\mathrm{OH}$ reflected nutritional (fat and salt content of food prepared $\mathrm{OH}$ ) and food safety concerns with regard to eating $\mathrm{OH}$. Adolescents of the highest tertile of this pattern ate $\mathrm{OH}$ less frequently compared to those in 280 the lower tertiles. There is very little information on how nutrition or health consciousness influences eating $\mathrm{OH}$. Yen et al. previously reported differences in foods consumed at home and $\mathrm{OH}$ by levels of nutritional knowledge (Yen et al., 2008). Use of fast food restaurants was inversely associated with concerns about healthy eating in a sample of US adolescents (French et al., 2001) and self-rated health (Satia et al., 2004). In addition, some have argued 285 that health conscious consumers eat $\mathrm{OH}$ less frequently compared to their peers and that specific actions are needed to reach this population to promote healthy eating $\mathrm{OH}$ (Lachat et al., 2011). 
Neither the Convenience nor the Nutritional and food safety concerned pattern was associated with differences in $\%$ energy from $\mathrm{OH}$ foods. This is likely attributable to the heterogeneity and type of the foods consumed when eating $\mathrm{OH}$. These foods included soups, fruits as well as high energy dense foods (Lachat et al., 2009).

The Convenience pattern, associated with higher frequencies of eating $\mathrm{OH}$, was negatively associated with total energy intake and energy density on a daily basis. This is in contrast with the available evidence. Various studies from industrialised countries have shown that frequency of eating $\mathrm{OH}$ is associated with higher energy intakes per day (French et al., 2001; Satia et al., 2004; Taveras et al., 2005). In our study, soups and fruits featured as the most popular $\mathrm{OH}$ foods and the energy density of $\mathrm{OH}$ foods was lower compared to foods prepared at home $(137.5 \pm 95.0 \mathrm{kcal} / 100 \mathrm{~g}$ vs. $222.8 \pm 51.8 \mathrm{kcal} / 100 \mathrm{~g})$.

We observed important differences between urban and rural areas. Eating $\mathrm{OH}$ was more important in the diet of urban children compared to that of the rural ones and the association between the Convenience pattern and the frequency of eating $\mathrm{OH}$ was slightly more pronounced in urban areas. This corresponds with available data on street food consumption in low and middle income countries (Dawson \& Canet, 1991; FAO, 1990). We previously documented how in urban areas, fruits and beef noodle soups were relatively more frequently consumed as $\mathrm{OH}$ foods (Lachat et al., 2009). In rural areas, sweet desserts, fried meat, bread with liver pâté, rice doughnuts topped the list of $\mathrm{OH}$ foods.

Neither gender nor nutrition status significantly modified the relationship with the patterns identified and the dietary outcomes or socio-economic status. Although females ate more frequently $\mathrm{OH}$ and had higher \% energy intakes from $\mathrm{OH}$ food, we did not observe gender 
differences in the associations of the patterns and the frequency of eating $\mathrm{OH}$ or the $\%$ energy contribution of eating $\mathrm{OH}$ on a daily basis. Similarly, although overweight children had a slightly (although marginally not significant) higher energy contribution from $\mathrm{OH}$ eating compared to their normal BMI peers, adding the nutrition status to the models did not significantly modify the associations.

320 Adolescents with higher amounts of pocket money ate $\mathrm{OH}$ more frequently compared to their peers. In addition, adolescents from wealthier households had a higher energy contribution from foods $\mathrm{OH}$. The socio-economic gradient in dietary quality of adolescents has been described earlier (Darmon \& Drewnowski, 2008; Neumark-Sztainer et al., 2003; Ruxton \& Kirk, 1996). Our findings expand the available evidence and suggest that a higher socioeconomic status can mediate dietary intake through differences in eating $\mathrm{OH}$.

We acknowledge a number of limitations of this study. We used convenience sampling to recruit our participants which impairs generalisation of our findings (Lachat et al., 2009). We did not attempt to exclude over and under reporting children due to lack of valid equations to calculate the Basal Metabolic Rate of non-Caucasian adolescents (Torun, 2005). We did not collect information regarding the price of the foods in the analysis. We acknowledge that the financial cost of eating $\mathrm{OH}$ is a potential important covariate for this analysis which was not assessed. Lastly, we used factor analysis to identify patterns in items in the questionnaire. This approach is appropriate for this study since it takes the relationships between items into account to identify patterns. The disadvantage however, is that the findings are largely data driven and require additional studies to be generalised. Despite these conceptual differences however, the findings of our study are robust, sensible and confirm various previous results of studies that have looked at eating $\mathrm{OH}$. 
340 In conclusion, we report that convenience and to a lesser extent nutritional and food safety concerns are important factors associated with the frequency of eating $\mathrm{OH}$ in Vietnamese adolescents in particular those residing in rural areas. In addition, pocket money and accumulated household wealth were significant predictors of frequency of eating $\mathrm{OH}$ and $\%$ energy contribution of $\mathrm{OH}$ respectively. 


\section{Acknowledgements}

We thank the staff of the staff of the Department of Occupational and School Nutrition and Prof. Khan Director of the National Institute of Nutrition of Vietnam and teachers and pupils

350 of the schools selected in the study. This study was funded by both the Nutricia Research Foundation and Nutrition Third World. The sponsors were not involved in the study design, collection, analysis or interpretation of the data. The first and corresponding authors had access to all data at all times and had the final responsibility to submit the manuscript for publication.

\section{Conflict of interest}

The authors declare that they have no competing interests. LC, KLNB and KP designed and carried out the study. LC drafted the manuscript and LC, HTTT, NE and VR analysed the data. All authors critically revised the drafted manuscript. 


\section{References}

365 Adair LS , Popkin BM (2005). Are child eating patterns being transformed globally? Obesity Research, 13, 1281-1299.

Bere E, van Lenthe F, Klepp KI and Brug J (2008). Why do parents education level and income affect the amount of fruits and vegetables adolescents eat. European Journal of Public Health, 18, 611-615.

370 Bezerra IN , Sichieri R (2009). Eating out of home and obesity: a Brazilian nationwide survey. Public Health Nutrition, 12, 2037-2043.

Cole TJ, Bellizzi MC, Flegal KM and Dietz WH (2000). Establishing a standard definition for child overweight and obesity worldwide: international survey. British Medical Journal, $320,1240-1243$.

375 Cole TJ, Flegal KM, Nicholls D and Jackson AA (2007). Body mass index cut offs to define thinness in children and adolescents: international survey. British Medical Journal, 335, 194197.

Cummins S , Macintyre S (2006). Food environments and obesity - neighbourhood or nation? International Journal of Epidemiology, 35, 100-104.

380 Darmon N , Drewnowski A (2008). Does social class predict diet quality? American Journal of Clinical Nutrition, 87, 1107-1117.

Davis B , Carpenter C (2009). Proximity of Fast-Food Restaurants to Schools and Adolescent Obesity. American Journal of Public Health, 99, 505-510. 
Dawson RJ and Canet C (1991). International activities in street foods. Food Control, 2, 135139.

FAO. (1990). Street foods. FAO Food and Nutrition paper 46. Report of an FAO consultation. Jogjakarta, Indonesia December 1988. Rome, Food and Agricultural Organisation of the United Nations.

French SA, Story M, Neumark-Sztainer D, Fulkerson JA and Hannan P (2001). Fast food 390 restaurant use among adolescents: associations with nutrient intake, food choices and behavioral and psychosocial variables. International Journal of Obesity, 25, 1823-1833.

Hong TK, Dibley MJ, Sibbritt D, Binh PNT, Trang NHHD and Hanh TTM (2007). Overweight and obesity are rapidly emerging among adolescents in Ho Chi Minh City, Vietnam, 2002-2004. International Journal of Pediatric Obesity, 2, 194-201.

395 Jackson RT, Rashed M and Saad-Eldin R (2003). Rural urban differences in weight, body image, and dieting behavior among adolescent Egyptian schoolgirls. International Journal of Food Science \& Nutrition, 54, 1-11.

Kaiser HF (1960). The Application of Electronic Computers to Factor Analysis. Educational \& Psychological Measurement, 20, 141-151.

400 Kant AK, Graubard BI (2004). Eating out in America, 1987-2000: trends and nutritional correlates. Preventive Medicine, 38, 243-249.

Kelder SH, Perry CL, Klepp KI and Lytle LL (1994). Longitudinal Tracking of Adolescent Smoking, Physical-Activity, and Food Choice Behaviors. American Journal of Public Health, $84,1121-1126$. 
405 Kennedy GL, Pedro MR, Seghieri C, Nantel G and Brouwer I (2007). Dietary diversity score is a useful indicator of micronutrient intake in non-breast-feeding Filipino children. Journal of Nutrition, 137, 472-477.

Kremers SPJ, de Bruijn GJ, Droomers M, van Lenthe F and Brug J (2007). Moderators of environmental intervention effects on diet and activity in youth. American Journal of

410 Preventive Medicine, 32, 163-172.

Lachat C, Le NBK, Nguyen CK, Nguyen QD, Nguyen DVA, Roberfroid D et al. (2009). Eating out of home in Vietnamese adolescents: socioeconomic factors and dietary associations. American Journal of Clinical Nutrition, 90, 1648-1655.

Lachat C, Naska A, Trichopoulou A, Engeset D, Fairgrieve A, Ávila Marques H et al. (2011).

415 Essential actions for caterers to promote healthy eating out among European Consumers: results from a participatory stakeholder analysis in the HECTOR project. Public Health Nutrition, 14, 193-202.

Lien N, Jacobs DR and Klepp KI (2002). Exploring predictors of eating behaviour among adolescents by gender and socio-economic status. Public Health Nutrition, 5, 671-681.

420 Likert R (1932). A Technique for the Measurement of Attitudes. Archives of Psychology, 140.

Lucan SC, Barg FK and Long JA (2010). Promoters and Barriers to Fruit, Vegetable, and Fast-Food Consumption Among Urban, Low-Income African Americans-A Qualitative Approach. American Journal of Public Health, 100, 631-635. 
425 Milligan RAK, Burke V, Beilin LJ, Dunbar DL, Spencer MJ, Balde E et al. (1998). Influence of gender and socio-economic status on dietary patterns and nutrient intakes in 18-year-old Australians. Australian New Zealand Journal of Public Health, 22, 485-493.

National Institute of Nutrition (1972). Food products in Vietnam: composition and nutritive value Hanoi: NIN.

430 Neumark-Sztainer D, Hannan PJ, Story M, Croll J and Perry C (2003). Family meal patterns: Associations with sociodemographic characteristics and improved dietary intake among adolescents. Journal of the American Dietetic Association, 103, 317-322.

Orfanos P, Naska A, Trichopoulou A, Grioni S, Boer JMA, van Bakel MME et al. (2009). Eating out of home: energy, macro- and micronutrient intakes in 10 European countries. The 435 European Prospective Investigation into Cancer and Nutrition. European Journal of Clinical Nutrition, 63, S239-S262.

Ruxton CHS , Kirk TR (1996). Relationships between social class, nutrient intake and dietary patterns in Edinburgh schoolchildren. International Journal of Food Science and Nutrition, 47, 341-349.

440 Rydell SA, Harnack LJ, Oakes JM, Story M, Jeffery RW and French SA (2008). Why Eat at Fast-Food Restaurants: Reported Reasons among Frequent Consumers. Journal of the American Dietetic Association, 108, 2066-2070.

Sandvik C, Gjestad R, Samdal O, Brug J and Klepp KI (2010). Does socio-economic status moderate the associations between psychosocial predictors and fruit intake in schoolchildren? 445 The Pro Children study. Health Education Research, 25, 121-134. 
Satia JA, Galanko JA and Siega-Riz AM (2004). Eating at fast-food restaurants is associated with dietary intake, demographic, psychosocial and behavioural factors among African Americans in North Carolina. Public Health Nutrition, 7, 1089-1096.

Story M, Neumark-Sztainer D and French S (2002). Individual and environmental influences 450 on adolescent eating behaviors. Journal of the American Dietetic Association, 102, S40-S51.

Swinburn B, Egger G and Raza F (1999). Dissecting obesogenic environments: The development and application of a framework for identifying and prioritizing environmental interventions for obesity. Preventive Medicine, 29, 563-570.

Taveras EM, Berkey CS, Rifas-Shiman SL, Ludwig DS, Rockett HRH, Field AE et al. (2005). Association of consumption of fried food away from home with body mass index and diet quality in older children and adolescents. Pediatrics, 116, E518-E524.

Thang NM, Popkin B (2003). Child malnutrition in Vietnam and its transition in an era of economic growth. Journal of Human Nutrition \& Dietetics, 16, 233-244.

Thompson OM, Ballew C, Resnicow K, Must A, Bandini LG, Cyr H et al. (2004). Food 460 purchased away from home as a predictor of change in BMI z-score among girls. International Journal of Obesity, 28, 282-289.

Torun B (2005). Energy requirements of children and adolescents. Public Health Nutrition, 8, 968-993.

van der Horst K, Oenema A, Ferreira I, Wendel-Vos W, Giskes K, van Lenthe F et al. (2007). 465 A systematic review of environmental correlates of obesity-related dietary behaviors in youth. Health Education Research, 22, 203-226. 
van Lierop A, Nguyen VN, Doak C, Le QH, Tran QB, Hoekstra J et al. (2008). Regional clustering of anthropometric dimensions of primary school children in rural and suburban Vietnam. Asia Pacific Journal of Clinical Nutrition, 17, 603-607. WA (2001). The role of street foods in the dietary pattern of two low-income groups in Nairobi. European Journal of Clinical Nutrition, 55, 562-570.

Vandevijvere S, Lachat C, Kolsteren P and Van Oyen H (2009). Eating out of home in Belgium: current situation and policy implications. British Journal of Nutrition, 102, 921475 928.

Wang YF, Bentley ME, Zhai FY and Popkin BM (2002). Tracking of dietary intake patterns of Chinese from childhood to adolescence over a six-year follow-up period. Journal of Nutrition, 132, 430-438.

Warde A and Martens L (1998). Eating out and the commercialisation of mental life. British $480 \quad$ Food Journal, 100, 147-153.

WHO (2003). Diet, Nutrition and the Prevention of Chronic Diseases. WHO Technical Report Series nr 916 Geneva: World Health Organisation.

Willett WC, (1998). Nutritional epidemiology. (vols. 30) New York: Oxford University Press.

485 Williams R (2006). Generalized ordered logit /partial proportional-odds models for ordinal dependent variables. Stata Journal, 6, 58-82.

Yen ST, Lin BH and Davis CG (2008). Consumer knowledge and meat consumption at home and away from home. Food Policy, 33, 631-639. 
You W, Zhang G, Davy BM, Carlson A and Lin BH (2009). Food Consumed Away from 490 Home Can Be a Part of a Healthy and Affordable Diet. Journal of Nutrition, 139, 1994-1999. 
Table 1: Factor loadings of items associated with eating $\mathrm{OH}^{*}$

\begin{tabular}{|c|c|c|}
\hline & $\begin{array}{c}\text { Convenience } \\
\text { pattern }\end{array}$ & $\begin{array}{c}\text { Nutrition } \\
\text { and food } \\
\text { safety } \\
\text { concerned } \\
\text { pattern }\end{array}$ \\
\hline$\%$ of variance explained & $35.5 \%$ & $23.6 \%$ \\
\hline Eigenvalue of the factor & 2.3 & 1.5 \\
\hline \multicolumn{3}{|l|}{ Factors } \\
\hline OH foods are prepared fast & 0.54 & -0.03 \\
\hline Eating $\mathrm{OH}$ is cheap & 0.46 & -0.02 \\
\hline $\mathrm{OH}$ foods are tasty & 0.69 & 0.02 \\
\hline It is near to the school & 0.43 & -0.07 \\
\hline I can meet friends when eating $\mathrm{OH}$ & 0.43 & -0.04 \\
\hline Foods I eat $\mathrm{OH}$ cannot be eaten at home & 0.16 & 0.00 \\
\hline There is more variety when eating $\mathrm{OH}$ & 0.63 & 0.07 \\
\hline Eating $\mathrm{OH}$ is more stylish & 0.25 & -0.07 \\
\hline I don't like to cook at home & 0.49 & -0.09 \\
\hline I don't know foods $\mathrm{OH}$ are prepared & 0.05 & 0.15 \\
\hline I don't care whether eating $\mathrm{OH}$ are healthy or not & 0.16 & -0.08 \\
\hline Eating $\mathrm{OH}$ is expensive & -0.11 & 0.18 \\
\hline It cannot satisfy my appetite when eating $\mathrm{OH}$ & -0.05 & 0.11 \\
\hline I am afraid older people will think I am not a good student when eating $\mathrm{OH}$ & -0.05 & 0.22 \\
\hline There is no family atmosphere when eating $\mathrm{OH}$ & 0.00 & 0.24 \\
\hline Food prepared at home is more tasty & 0.15 & 0.25 \\
\hline $\mathrm{OH}$ food is unhygienic & 0.05 & 0.35 \\
\hline $\mathrm{OH}$ food is too fat & 0.01 & 0.74 \\
\hline OH food contains too much salt & -0.03 & 0.75 \\
\hline Eating $\mathrm{OH}$ is a part of modern life & 0.41 & -0.18 \\
\hline
\end{tabular}

* Result from factor analysis of associations of eating $\mathrm{OH}$ in Vietnamese adolescents ( $\mathrm{n}=502)$,

Factor loadings $>0.3$ are indicated in bold and were considered meaningful to identify a pattern 
Table 2: Dietary characteristics of tertiles of "Convenience" and "Nutrition and food safety concerned" patterns towards eating OH in Vietnamese adolescents

\begin{tabular}{|c|c|c|c|c|c|c|c|c|}
\hline & \multicolumn{4}{|c|}{ Convenience pattern } & \multicolumn{4}{|c|}{ Nutrition and food safety concerned pattern } \\
\hline & Low & Middle & High & $\mathrm{P}^{*}$ & Low & Middle & High & $\mathrm{P}^{*}$ \\
\hline 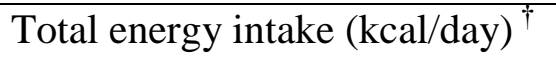 & $2540.4 \pm 927.5$ & $2296.7 \pm 808.3$ & $2313.2 \pm 842.1$ & 0.03 & $2476.8 \pm 826.9$ & $2353.2 \pm 879.3$ & $2320.3 \pm 888.2$ & 0.09 \\
\hline $\operatorname{DDS}^{\dagger, *}$ & $6.8 \pm 1.4$ & $6.8 \pm 1.4$ & $6.9 \pm 1.4$ & 0.80 & $6.9 \pm 1.4$ & $6.8 \pm 1.3$ & $6.7 \pm 1.5$ & 0.50 \\
\hline Energy from fat $(\%)^{\dagger}$ & $17.3 \pm 7.2 \%$ & $17.9 \pm 7.2 \%$ & $18.7 \pm 6.8 \%$ & 0.10 & $18.6 \pm 7.0 \%$ & $17.3 \pm 7.0 \%$ & $18.0 \pm 7.2 \%$ & 0.80 \\
\hline $\mathrm{Na}(\mathrm{mg} / \text { day })^{\dagger, \S}$ & $1576.8 \pm 874.2$ & $1392.3 \pm 998.7$ & $1461.8 \pm 875.4$ & 0.60 & $1595.4 \pm 925.8$ & $1381.4 \pm 866.1$ & $1454.2 \pm 955.7$ & 0.26 \\
\hline Vitamin A (RE/day $)^{\dagger, \S, \mid l}$ & $950.4 \pm 1104.8$ & $825.4 \pm 661.8$ & $960.4 \pm 1056.8$ & 0.88 & $937.7 \pm 1202.7$ & $915.0 \pm 847.9$ & $883.9 \pm 789.2$ & 0.57 \\
\hline $\mathrm{Fe}(\mathrm{mg} / \text { day })^{\dagger, \S}$ & $17.2 \pm 8.9$ & $16.2 \pm 8.3$ & $16.5 \pm 8.1$ & 0.10 & $17.2 \pm 8.1$ & $16.5 \pm 8.9$ & $16.1 \pm 8.3$ & 0.98 \\
\hline $\mathrm{Zn}(\mathrm{mg} / \text { day })^{\dagger, \S}$ & $11.5 \pm 5.6$ & $10.2 \pm 4.5$ & $10.5 \pm 4.2$ & 0.29 & $11.2 \pm 4.8$ & $10.5 \pm 5.0$ & $10.5 \pm 4.7$ & 0.33 \\
\hline
\end{tabular}

500 * Kruskal-Wallis test comparing differences in dietary intake between different tertiles of Convenience and Nutrition and food safety concerned pattern of eating $\mathrm{OH}^{\dagger}$ Means and SD, ${ }^{\star}$ DDS is the Dietary diversity score expressed as number of food groups for which $>10 \mathrm{~g}$ was consumed, ${ }^{\S}$ The estimates were adjusted for total energy intake when comparing intakes between groups as suggested by Willet ${ }^{(49)}$. The tabulated figures are non-adjusted. ${ }^{||}$RE: Retinol equivalents 
Table 3: Convenience pattern and socio-economic predictors as factors associated with

Frequency of \% energy contribution eating $\mathrm{OH}^{*} \quad$ from $\mathrm{OH}$ foods ${ }^{\dagger}$

\begin{tabular}{lcccc}
\cline { 2 - 5 } & $\mathbf{O R}^{\ddagger}$ & $\mathbf{P}$ & OR & P \\
\hline Convenience pattern $\mathrm{OH}^{\S}(\mathrm{n}=502)$ & 1.51 & $<0.001$ & 0.96 & 0.75
\end{tabular}

Accumulated household wealth ${ }^{||}$

High ( $\mathrm{n}=237)$ vs. lower $(\mathrm{n}=265)$

$1.24 \quad 0.34$

Pocket money |

High $(n=183)$ vs. lower $(n=319)$

Gender

Male ( $n=182)$ vs. female $(n=20)$

$0.66 \quad 0.24$

Location $^{||}$

Rural ( $\mathrm{n}=194)$ vs. urban $(\mathrm{n}=308)$

Education of father ${ }^{\mid l}$

College, university or higher education

$(n=159)$ vs. Senior secondary or lower

$(\mathrm{n}=289)$

Education of mother ${ }^{\prime \mid}$

College, university or higher education $(n=158)$ vs. Senior secondary or lower $(\mathrm{n}=292)$

Nutrition status ${ }^{\vee}$

Overweight ( $\mathrm{n}=22)$ vs normal BMI

children $(\mathrm{n}=367)$

* Categorical regression analysis with frequency of eating $\mathrm{OH}$ per week (categorised as tertiles) as dependent variable ${ }^{\dagger}$ Categorical regression analysis with \% energy contribution per day from $\mathrm{OH}$ foods (categorised as tertiles) as dependent variable All models were adjusted for clustering in schools. Predictors with $\mathrm{P}<0.20$ in bivariate models were included in the adjusted models $\$$ Odds ratio, ${ }^{\S}$ Variable representing a pattern of

510 Convenience with regard to eating $\mathrm{OH}$. The variable was obtained from factor analysis and categorised as tertiles. ${ }^{\prime \mid}$ The highest category is the highest tertile and lower the 2 lowest tertiles. The categorisation was done a priori and separately for rural and urban areas. ${ }^{\mathrm{I}} \mathrm{Not}$ included in the adjusted model since $\mathrm{P}>0.20$ in the crude model with bivariate associations. ${ }^{V}$ Underweight children did not differ in frequency and energy contribution from $\mathrm{OH}$ eating and this category was therefore not included in the models. 

predictors as factors associated with of eating $\mathrm{OH}$ in Vietnamese adolescents

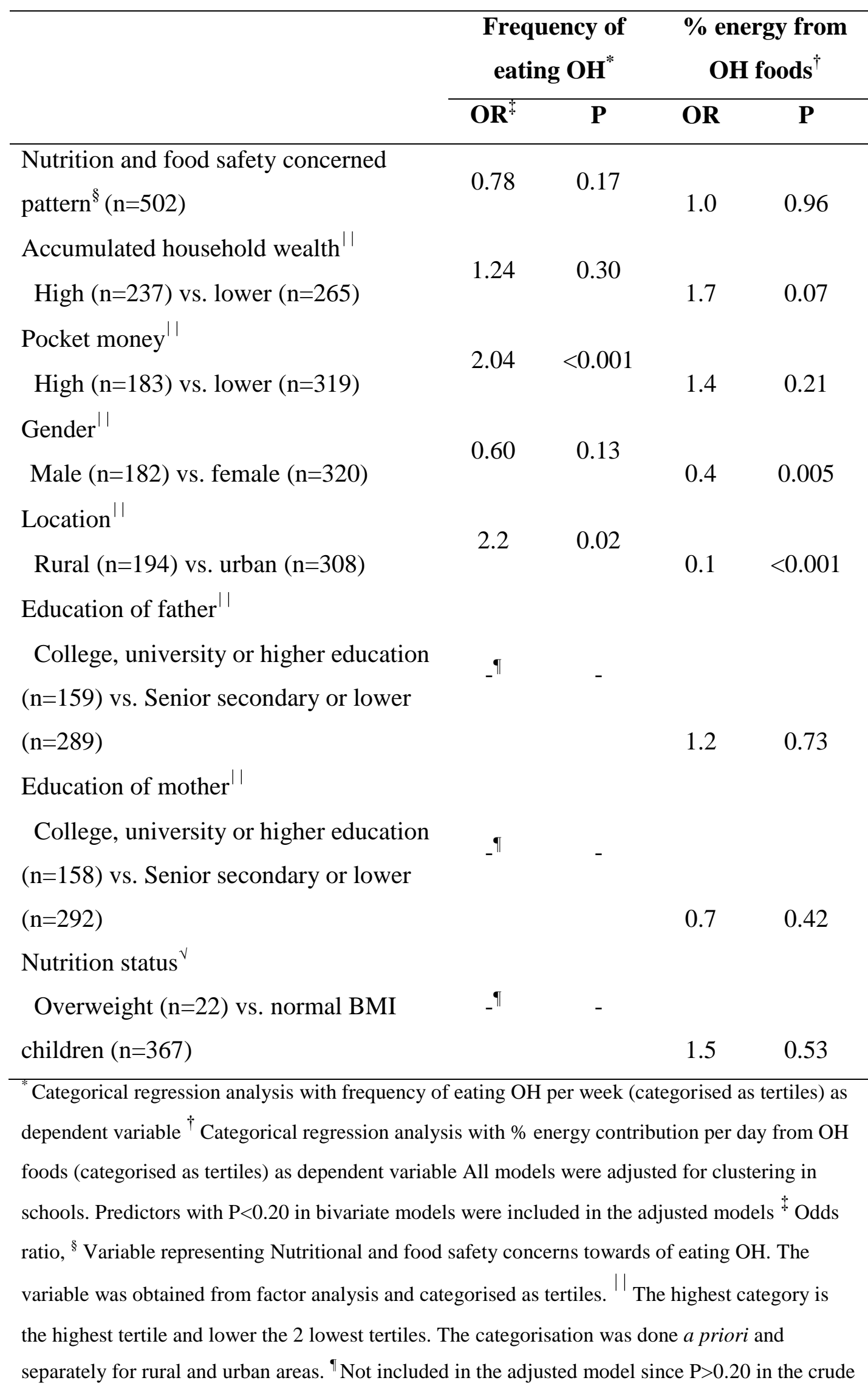


1 model with bivariate associations. ${ }^{\sqrt{ }}$ Underweight children did not differ in frequency and energy

2 contribution from $\mathrm{OH}$ eating and this category was therefore not included in the models.

3 
1 Figure 1: Screeplot of eigenvalues after the factor analysis

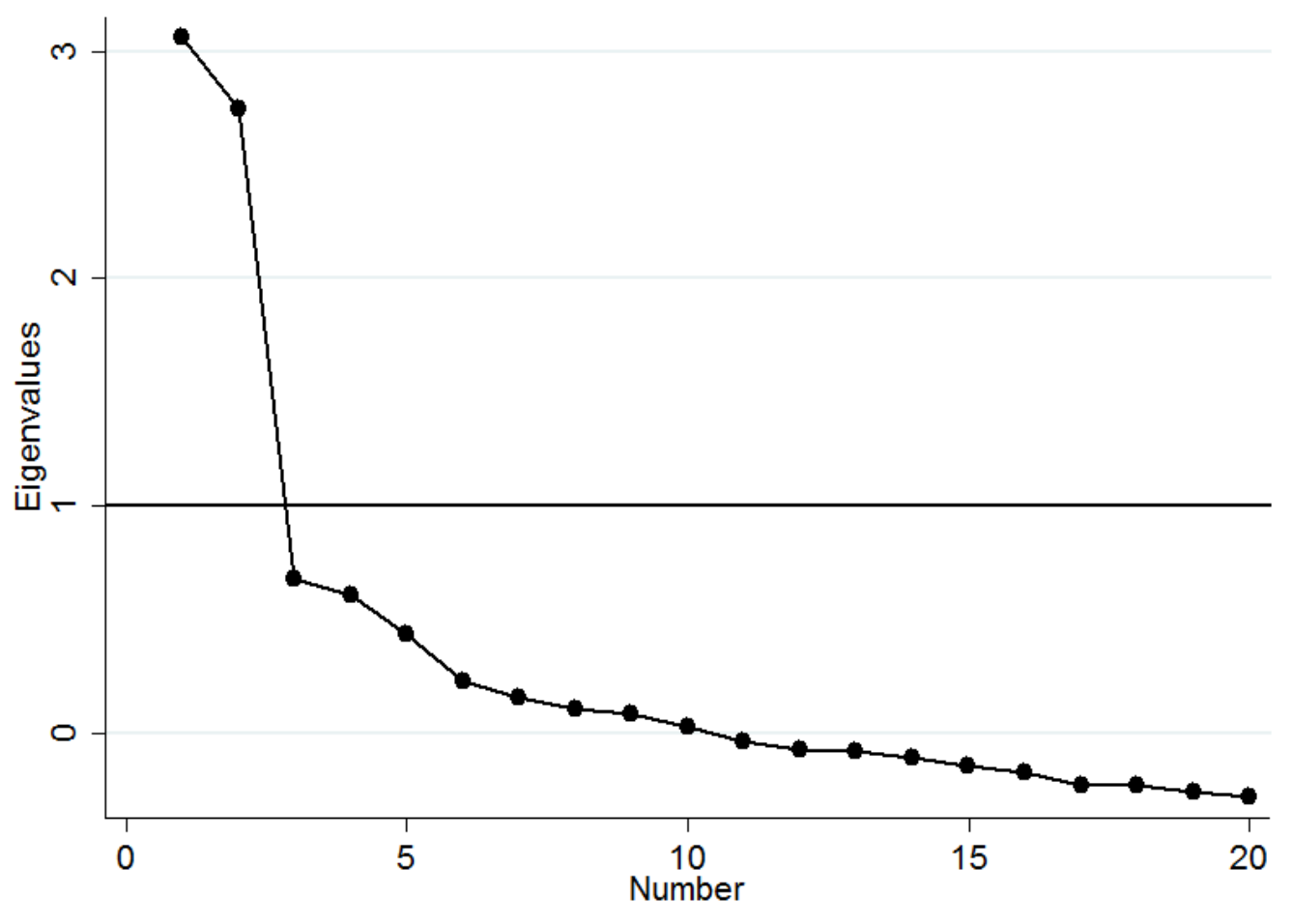

2 
2 adolescents as included in the questionnaire

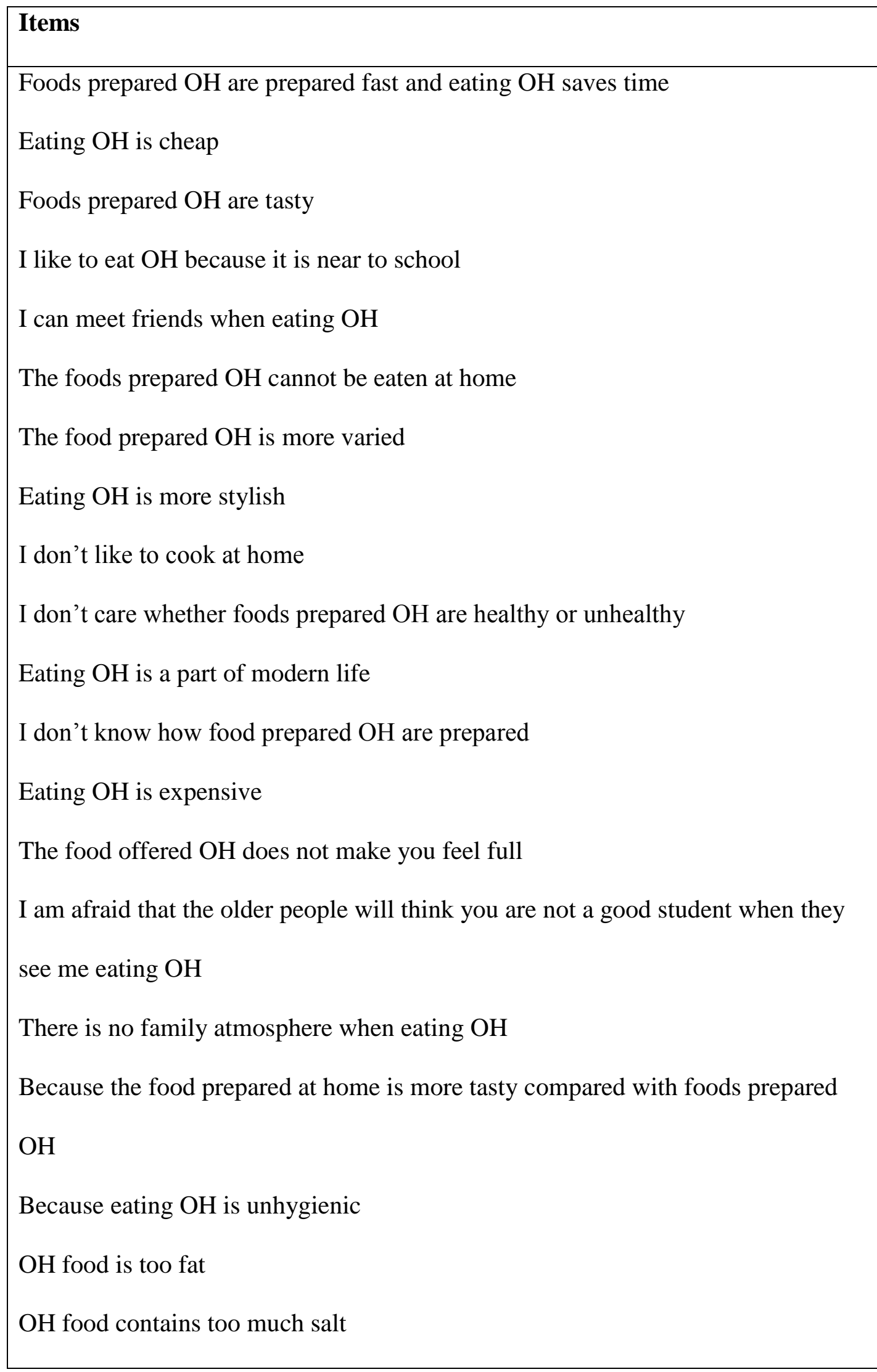

